\title{
Caracterização termofísica de solo laterítico para produção de taipa
}

\author{
Thermophysical characterization of \\ lateritic soil for manufacturing \\ rammed earth walls
}

Carol Cardoso Moura Cordeiro ${ }^{1}$, Douglas Queiroz Brandão ${ }^{2}$, Luciane Cleonice Durante ${ }^{1}$, Ivan Julio Apolônio Callejas ${ }^{1}$, Caio Augusto Barbosa de Campos ${ }^{1}$

\footnotetext{
${ }^{1}$ Laboratório de Tecnologia e Conforto Ambiental - LATECA - FAET/UFMT CEP: 78060-900, Cuiabá, MT, Brasil.

${ }^{2}$ Departamento de Engenharia Civil - FAET/UFMT CEP: 78060-900, Cuiabá, MT, Brasil. e-mail: carolcardoso.eng@gmail.com, luciane.durante@hotmail.com, ivancallejas1973@gmail.com, caioabcampos@gmail.com,douglas.brandao@gmail.com
}

\section{RESUMO}

Considerando a necessidade atual de minimização dos impactos ambientais oriundos da cadeia de produção da construção civil, as técnicas construtivas com terra constituem-se em alternativas de grande potencialidade, uma vez que a matéria-prima pode estar disponível no próprio local e não são incorporados processos de queima na produção dos materiais. Além disso, a depender do tipo de solo escolhido e da qualidade da sua execução, paredes de terra podem apresentar elevada durabilidade. Entretanto, outras vantagens abordadas, como o conforto térmico da construção com terra são, muitas vezes, tratadas de forma empírica. Nesse sentido, o objetivo geral deste artigo é determinar as propriedades termofísicas de um solo definido como cascalho laterítico, do município de Cuiabá - MT, visando seu emprego na construção com terra. A metodologia consistiu em: ensaios de caracterização geotécnica do solo e ensaio in situ de transmitância térmica a partir de um corpo de prova de terra compactada. Os resultados indicaram transmitância térmica $\left(\mathrm{U}_{\mathrm{T}}\right)$ de $2,58 \mathrm{Wm}^{-}$ ${ }^{2} \mathrm{~K}^{-1}$, capacidade térmica $\left(\mathrm{C}_{\mathrm{T}}\right)$ de $228,12 \mathrm{kJm}^{-2} \mathrm{~K}^{-1}$, atraso térmico $(\varphi)$ de 5,12 horas, absortância térmica $(\alpha)$ de $61,63 \%$ e fator solar de 6,30\% para o corpo de prova de $0,08 \mathrm{~m}$ de espessura, atendendo parcialmente aos parâmetros estabelecidos pela norma técnica. Em relação aos valores projetados para parede de taipa com espessura de $0,30 \mathrm{~m}\left(\mathrm{U}_{\mathrm{T}}=1,43 \mathrm{Wm}^{-2} \mathrm{~K}^{-1} ; \mathrm{C}_{\mathrm{T}=} 855,46 \mathrm{kJm}^{-2} \mathrm{~K}^{-1}\right.$; e, $\varphi=15,51$ horas $)$, constatou-se o atendimento de todos os requisitos das zonas 4, 6 e 7 . Conclui-se que o solo ensaiado, se validado quanto a funções estruturais, pode ser utilizado em edificações nas zonas brasileiras elencadas.

Palavras-chave: Terra compactada. Edificações sustentáveis. Desempenho térmico.

\section{ABSTRACT}

Considering the current need to minimize environmental impacts arising from the civil construction chain, constructive techniques with earth are alternatives of great potentiality, since the material is available on site and no burning processes are incorporated in the production of walls. In addition, depending on the type of soil chosen and the quality of its execution, earth walls present high durability. However, other advantages addressed, such as the thermal comfort of construction with earth are often treated empirically. In this sense, the general objective of this article is to determine the thermophysical properties of a soil defined as lateritic gravel, from the Cuiabá-MT municipality. The methodology consisted of two steps: tests of geotechnical characterization of the soil and in situ test of thermal transmittance from a sample. The results indicate thermal transmission $\left(\mathrm{U}_{\mathrm{T}}\right)$ of $2.58 \mathrm{Wm}^{-2} \mathrm{~K}^{-1}$, thermal capacity $(\mathrm{CT})$ of $228.12 \mathrm{kJm}^{-2} \mathrm{~K}^{-1}$, thermal time $(\varphi)$ of 5.12 hours, thermal absortance of $61.63 \%$ and solar factor of $6.30 \%$ for test body of $0,08 \mathrm{~m}$ of thickness; In relation to the mean values of rammed earth with a thickness of $0.30 \mathrm{~m}\left(\mathrm{U}_{\mathrm{T}}=1.43 \mathrm{Wm}^{-2} \mathrm{~K}^{-1} ; \mathrm{C}_{\mathrm{T}}=855.46 \mathrm{kJm}^{-}\right.$ ${ }^{2} \mathrm{~K}^{-1}$; and, $\varphi=15.51$ hours) the same meets all the requirements of zones 4,6 and 7 . It is concluded that this soil, if validated for one of the functions that can be, can be used in the buildings in the Brazilians areas listed.

Keywords: Rammed earth. Green Building. Thermal performance. 


\section{INTRODUÇÃO}

O revés ambiental relacionado ao crescimento infrene do setor construtivo, exemplificado pelo alto consumo de recursos naturais e emissão de poluentes, tanto na produção de insumos quanto na execução e demolição de obras de engenharia, tem influenciado a busca por construções de menor impacto ambiental.

Em vista disso, surge a motivação pelo desenvolvimento de métodos construtivos que promovam menor dispêndio de grandes somas energéticas para a sua produção, com uso racional de matérias-primas abundantes, não poluentes, duráveis e passíveis de reaproveitamento. Atendendo a essas premissas, a terra, utilizada no passado em habitações primitivas, tem voltado a ser vista como material de construção por ter baixo custo, disponibilidade na maioria das localidades terrestres (exceto às regiões geladas). Hodiernamente, as técnicas construtivas com terra têm passado por um processo de modernização, despertando, assim, o interesse de pesquisadores em países desenvolvidos como Portugal, Austrália, Suíça, Áustria, Reino Unido, Nova Zelândia e Estados Unidos, os quais têm demonstrando a evolução e a potencialidade para industrialização na contemporaneidade.

Um dos focos de desenvolvimento e aplicação atual da terra é a taipa, técnicas difundida, investigada e com diversas obras realizadas, independente da sua localização geográfica [1]. Também conhecida como taipa de pilão ou terra compactada, consiste na compactação de solo úmido, por camadas, dentro de fôrmas temporárias. Em sua aplicação tradicional, fôrmas artesanais de madeira são montadas e preenchidas com a terra, a qual é compactada em camadas de aproximadamente $10 \mathrm{~cm}$ até o preenchimento total das fôrmas que, em seguida, são removidas e recolocadas para executar a camada seguinte [2].

A compactação pode ser realizada de forma manual com um equipamento denominado pilão, com o objetivo de adensamento do material. Atualmente, a melhor qualidade das fôrmas, com placas e perfis industrializados, e com a compactação por meio de compactador pneumático, podem possibilitar a otimização do tempo de execução, resultando em um acabamento final mais refinado. Tem-se ainda, associada à terra, a possibilidade do uso de estabilizantes químicos, os quais modificam as propriedades do solo para aumento da resistência estrutural e hidrófuga das paredes.

Assim como nas demais construções que utilizam solo como material de construção, a taipa apresenta vantagens, principalmente no que tange ao cumprimento de requisitos sustentáveis. Outros aspectos como o de conforto térmico são comumente citados, sobretudo, quanto ao adequado isolamento proporcionado. A terra, quando compactada, tem capacidade estática elevada, tornando-a estável a altas temperaturas devido a densidade e espessura avantajadas das paredes [3]. Além disso, possui a capacidade de estabilizar e equilibrar a temperatura do ambiente interno de uma edificação, por intermédio da absorção ou liberação rápida de umidade para o meio, o que possibilita um menor ou quase nenhum consumo de energia para climatização $[4,5]$.

Entretanto, ao considerar o solo para uso na construção civil, é primordial uma análise prévia e criteriosa das suas características, visto que os processos de formação dos solos interferem na sua composição, justificando suas propriedades ilimitadas e sua heterogeneidade [6,7]. Sabendo-se que as características físicas e térmicas dos materiais influenciam nas trocas de energia com o meio, infere-se a importância de testar o solo como material de construção no que concerne a sua transmissão de calor, tendo em vista a necessidade de atender às normas existentes e possibilitar um melhor enquadramento na concepção do projeto de uma edificação [1].

No Brasil, a NBR 15220 [8] apresenta procedimentos de cálculo para avaliação de propriedades como transmitância, resistência e capacidade térmica dos materiais que compõem a envoltória da edificação, assim como determina alguns parâmetros para cada zona bioclimática brasileira, como a própria transmitância térmica, o atraso térmico, o fator solar de elementos e componentes de edificações e a absortância para radiação solar. Concomitantemente, a norma técnica NBR 15575-4 [9] apresenta os requisitos e critérios para verificação dos níveis mínimos de desempenho térmico de paredes externas, estabelecendo valores máximos admissíveis para a capacidade e transmitância térmica, de acordo com as zonas bioclimáticas brasileiras e com valores de absortância solar da superfície do material utilizado na envoltória.

Tendo em vista a relevância dessas propriedades na avaliação do desempenho de um material de construção visando a sua utilização como componente da envoltória, este artigo tem por objetivo determinar as propriedades físicas e térmicas de um solo tropical definido como cascalho laterítico, típico da baixada cuiabana, mas que é encontrado em várias regiões do Estado de Mato Grosso. Justifica-se a pesquisa pelo fato dela fornecer subsídios a respeito de tais propriedades das paredes de taipa, da qual se reconhece o notório conhecimento empírico, mas com incipiente conhecimento técnico-científico. As características técnicas aqui identificadas poderão ser aplicadas em projetos de edificações que se utilizem de tal técnica construtiva, podendo ser avaliada a habitabilidade da edificação quanto aos requisitos térmicos, segundo as normas de de- 
sempenho.

\section{MATERIAIS E MÉTODOS}

A estratégia metodológica adotada foi de natureza experimental, a partir de uma amostra de solo coletada no município de Cuiabá-MT, georreferenciada sob as coordenadas 15³3’51,6”S; 5603’30,63”O. Na Figura 1 é apresentado o fluxograma dos ensaios realizados, sendo os mesmos detalhados na sequência de acordo com os equipamentos e procedimentos metodológicos utilizados

A metodologia aplicada foi de natureza experimental, a partir de uma amostra de solo coletada no município de Cuiabá-MT, georreferenciada sob as coordenadas 15³3'51,6”S; 5603'30,63”O. Apresenta-se em forma de fluxograma (Figura 1) os ensaios de caracterização conduzidos na amostra, sendo os mesmos detalhados na sequência de acordo com os equipamentos e procedimentos metodológicos utilizados.

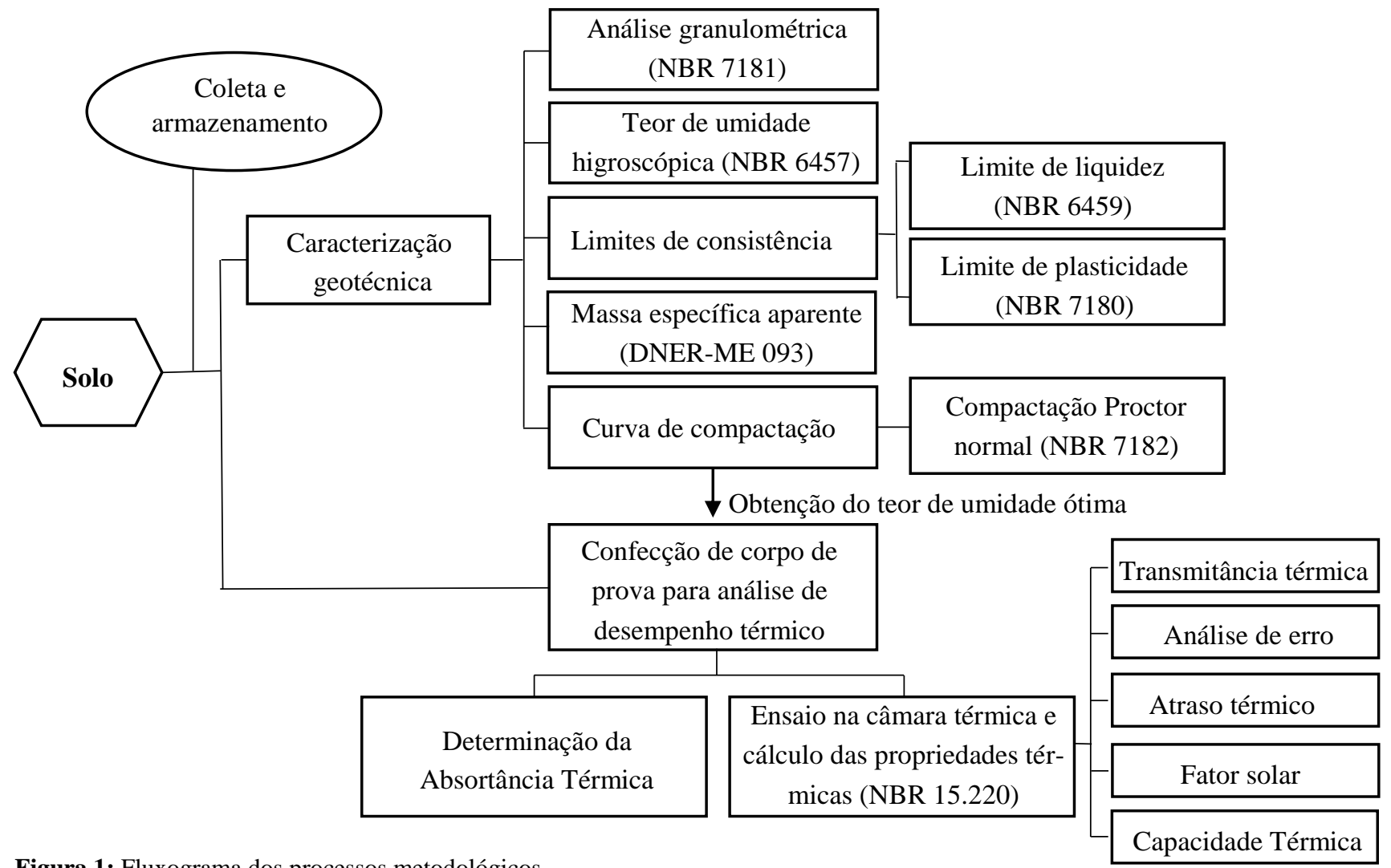

Figura 1: Fluxograma dos processos metodológicos.

\subsection{Coleta e armazenamento do material}

Coletou-se $200 \mathrm{~kg}$ de uma amostra deformada de solo que, após a retirada da camada superficial de $30 \mathrm{~cm}$ de profundidade do terreno natural contendo matéria orgânica, foi acondicionado em quatro sacos de $50 \mathrm{~kg}$ cada. Posteriormente, os sacos foram fechados, transportados e armazenados em laboratório, mantendo o teor de umidade natural e evitando a contaminação até o momento da sua utilização.

O solo escolhido é um cascalho laterítico, formado em regiões de clima tropical, característico da Baixada Cuiabana. Encontrado próximo a estradas e em áreas de expansão urbana, tem seu uso comumente empregado em base e sub-base de rodovias, por possuir elevado grau de compactação, rigidez e resistência [10]. A alta concentração de óxidos e hidróxidos de ferro e de alumínio encontrados na laterita proporciona uma cimentação natural ao solo ao longo do tempo [11], o que justifica a escolha do material para a pesquisa. Além disso, existe elevada ocorrência de jazidas na região, com uma reserva estimada de 94 milhões de metros cúbicos. Considerou-se que esse tipo de solo apresentaria características pertinentes, principalmente pela sua disponibilidade para o uso como material de construção em sistemas de vedações verticais de taipa.

\subsection{Caracterização Geotécnica}

Ensaios prévios de caracterização geotécnica do solo foram realizados na amostra para determinação do seu teor de umidade higroscópica, composição granulométrica, limites de consistência, massa específica dos 
grãos e compactação Proctor normal. Essa análise é fundamental para caracterizar a amostra e obter parâmetros necessários de umidade ótima e massa específica seca máxima para o desenvolvimento do corpo de prova utilizado no ensaio térmico.

\subsubsection{Análise Granulométrica}

Com a finalidade de obtenção da curva de distribuição granulométrica do solo em questão, realizaram-se os procedimentos estabelecidos pela norma técnica NBR 7181 [12]. Os ensaios foram realizados em três etapas: peneiramento grosso, sedimentação com defloculante e dispersor elétrico e peneiramento fino, respectivamente.

\subsubsection{Teor de umidade higroscópica}

A umidade higroscópica é definida como o teor de umidade do solo após sua secagem natural por exposição ao ar. O ensaio para determinação deste parâmetro foi realizado de acordo com a norma técnica NBR 6457 [13].

\subsubsection{Limites de consistência}

As amostras para os ensaios dos Limites de Atterberg foram preparadas também de acordo com a norma técnica NBR 6457 [13].

O Limite de Liquidez (LL) foi determinado de acordo com a norma técnica NBR 6459 [14]. O ensaio realizado no aparelho de Casagrande foi repetido cinco vezes e os resultados obtidos subsidiaram o cálculo dos pontos para elaboração do gráfico em escala logarítmica, no qual as ordenadas são os números de golpes e as abcissas os teores de umidade correspondentes.

O Limite de Plasticidade (LP) foi determinado de acordo com a norma técnica NBR 7180 [15]. O procedimento de ensaio foi repetido três vezes e o limite foi atribuído a média dos resultados das amostras, em $\%$.

Após a obtenção dos valores de LL e LP, calculou-se o Índice de Plasticidade (IP).

\subsubsection{Massa específica dos grãos}

A massa específica dos grãos depende diretamente dos minerais constituintes e da sua representatividade nesse solo. A sua determinação foi realizada pelo método do picnômetro, de acordo com a norma rodoviária ME 093 [16].

\subsubsection{Curva de compactação}

O ensaio de determinação da curva de compactação foi realizado segundo as especificações da norma técnica NBR 7182 [17] e a amostra selecionada seguiu as recomendações da norma técnica NBR 6457 [13], desprezando-se as partículas com dimensões superiores a $19 \mathrm{~mm}(3 / 4$ ").

Para o ensaio de compactação Proctor, foram preparados sete corpos de prova da amostra de solo, moldados em cilindros metálicos de $17,75 \mathrm{~cm}$ de altura e $15,17 \mathrm{~cm}$ de diâmetro, submetidos a energia Normal, compactados em 5 camadas, com 12 golpes por camada, com soquete metálico grande $(4,5 \mathrm{~kg}$ e 45,7 cm de altura de queda), visto que os cilindros pequenos (de aproximadamente $1000 \mathrm{~cm}^{3}$ de volume) devem ser empregados somente quando a amostra de solo passa integralmente na peneira de $4,8 \mathrm{~mm}$, condição não obtida no solo em estudo.

\subsection{Avaliação do desempenho térmico}

\subsubsection{Confecção do corpo de prova para análise de desempenho térmico}

O corpo de prova do ensaio térmico foi confeccionado com aproximadamente $23 \mathrm{~kg}$ do solo estudado, compactado com características de umidade e massa específica similares às obtidas nos ensaios de compactação Proctor normal. Utilizou-se no corpo de prova apenas partículas que passaram na peneira de $19,1 \mathrm{~mm}$, visto que em construção com terra recomenda-se granulometrias inferiores a $20 \mathrm{~mm}$ [18].

Um prisma de solo então foi moldado em fôrma em de madeira tipo MDF (chapas de 16 mm de espessura), confeccionada com medidas internas de $40,5 \mathrm{~cm}$ x $40,5 \mathrm{~cm}$ x $8 \mathrm{~cm}$, dimensões estas que atendem a abertura da câmara térmica na qual o corpo de prova é instalado com objetivo de oferecer resistência a passa- 
gem de calor entre a câmara quente e a câmara ambiental (fria), conforme procedimentos detalhados no item 2.3.3 (Figura 2 e Figura 3).

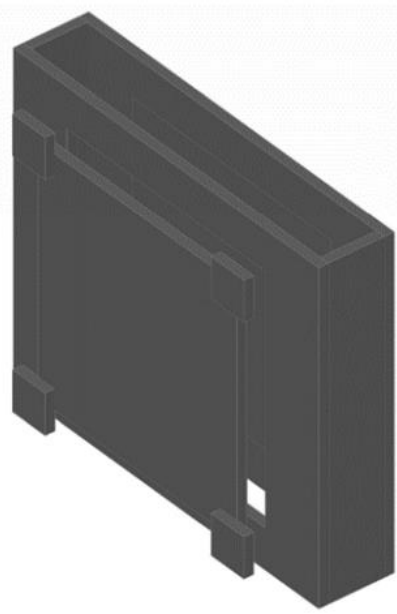

Figura 2: Projeto de fôrma para compactação de corpo de prova.

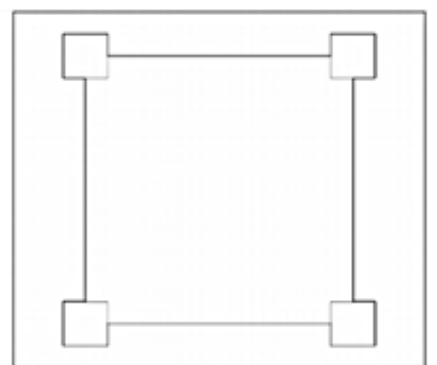

a)

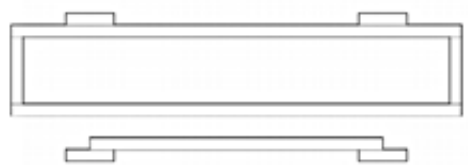

c)

Figura 3: Projeto de fôrma para compactação de corpo de prova. a) Vista Frontal, b) Vista Lateral, c) Corte.

O corpo de prova foi compactado com soquete grande em oito camadas, com 41 golpes distribuídos por camada com o intuito de obter mesma energia de compactação e, consequentemente, mesma massa específica seca máxima obtida no ensaio Proctor normal. Para facilitar a instalação do sensor fluxímetro e dos termopares para a medição da temperatura superficial, projetou-se uma fôrma com possibilidade de abertura (duas visitas de 34,5 cm x 34,5 cm nas duas faces de maior dimensão) (Figura 4-b), com a finalidade de manter o solo confinado e o corpo de prova estável durante os procedimentos de transporte e instalação, visando reduzir ao mínimo o corpo de prova aos esforços de compressão, tração e cisalhamento durante o manuseio da amostra.

A Figura 4 ilustra o procedimento de compactação do solo na fôrma, a desmontagem lateral da visita e a superfície do corpo de prova compactado, respectivamente. Após moldagem, os corpos de prova foram armazenados por 28 dias dentro do laboratório, protegidos de intempéries, para assim diminuir a influência da umidade do solo na transmissão do calor.

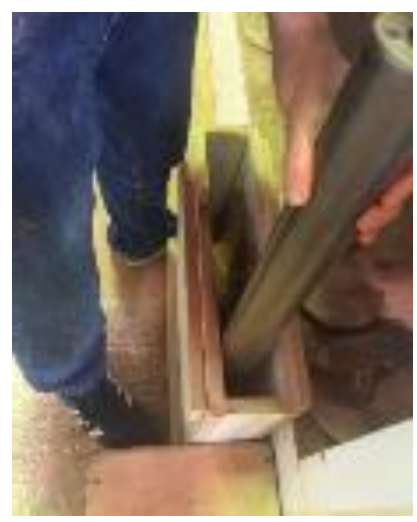

a)

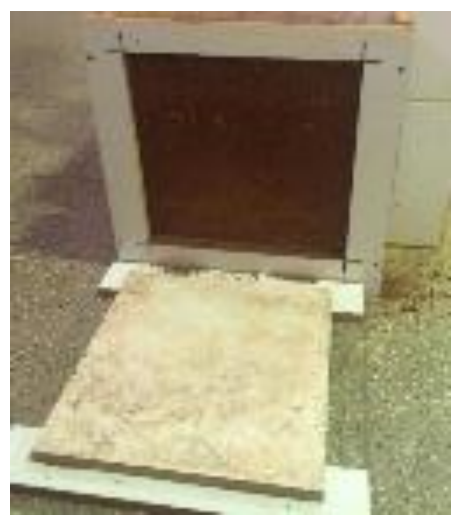

b)

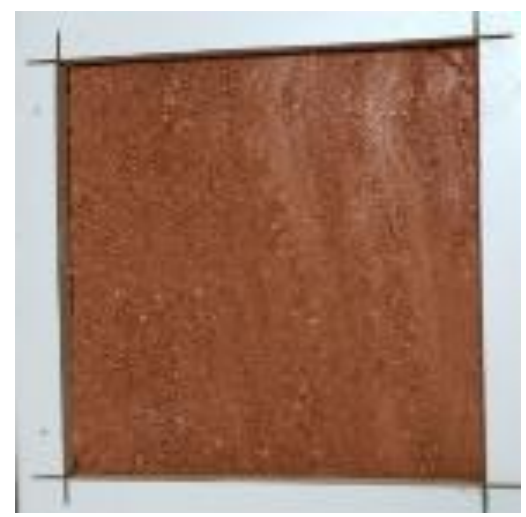

c)

Figura 4: Confecção do corpo de prova: a) compactação do solo na fôrma; b) desforma da visita; e, c) superfície do corpo de prova.

\subsubsection{Ensaio de determinação da absortância ( $\alpha$ )}

Na caracterização térmica, segundo a norma técnica NBR 15220 [8], existe a necessidade de quantificar a absortância à radiação solar do componente externo do sistema de vedação vertical, propriedade esta definida como o quociente da taxa de radiação solar absorvida por uma superfície pela taxa de radiação solar incidente 
sobre esta mesma superfície [8]. A determinação da absortância à radiação solar (número adimensional que varia de 0 à $100 \%$ ) é fundamental para a análise do desempenho térmico de um material, uma vez que quanto maior o seu percentual, maior será a absorção de radiação solar, impactando diretamente no aumento da temperatura superficial e, consequentemente, elevando as trocas térmicas e prejudicando o desempenho térmico de uma edificação.

Utilizou-se um espectrômetro ALTA II na medição desta propriedade no corpo de prova. O equipamento fornece valores de tensão, em milivolts $(\mathrm{mV})$, os quais são convertidos para valores de refletância. Esses valores são então determinados por meio de medições em onze diferentes comprimentos de onda $(\lambda)$ : sete na região visível (entre 470 e $700 \mathrm{mV}$ ) e quatro na região do infravermelho-próximo (entre 735 e 940 $\mathrm{mV}$ ) [19]. Nesta etapa, a refletância se refere ao quociente da taxa de radiação refletida pela superfície em estudo pela taxa de radiação emitidos nos espectros sobre esta mesma superfície por meio da utilização do equipamento ALTA II. Posteriormente, estes valores são transformados para a reflectância à radiação solar por meio do procedimento descrito na sequência.

O procedimento para a utilização do ALTA II foi realizado segundo o Centro Brasileiro de Eficiência Energética em Edificações (CB3E) [19], consistindo em:

a) Posicionar o equipamento sobre a superfície de uma folha de papel branca, de $75 \mathrm{~g} / \mathrm{m}^{2}$, utilizada como amostra de referência por apresentar valores de refletância espectral $(\rho)$ previamente conhecidos; a folha utilizada foi àquela caracterizada por Dornelles e Roriz [20] fazendo uso de um espectrofotômetro da marca Varian, modelo CARY 5G devido a sua maior precisão do equipamento; as características espectrais deste papel podem ser encontradas na Tabela 1; ao ligar o equipamento, deve-se registrar o valor inicial indicado no display, denominado de voltagem de fundo; Posteriormente, são pressionados os botões para a emissão da luz em cada comprimento de onda do equipamento, sendo os valores de reflectância indicados (em voltagem) no display do equipamento anotados (Figura 5); Para caracterização do corpo de prova, foram realizadas cinco leituras para cada comprimento de onda em diferentes posições, com o equipamento protegido com tecido preto em uma sala fechada, a fim de minimizar interferências da temperatura e da luz ambiente entre o corpo de prova e o aparelho.

Tabela 1: Refletâncias de referência obtidas em um espectrofotômetro da marca Varian, modelo CARY 5G para uma folha de papel branco comum de $75 \mathrm{~g} / \mathrm{m}^{2}$. Adaptado de Cardoso [21], baseado em Dornelles e Roriz [20].

\begin{tabular}{|c|c|c|c|c|c|c|c|c|c|c|c|}
\hline \multirow{2}{*}{$\begin{array}{l}\text { ALTA II } \\
\text { Cor }\end{array}$} & \multicolumn{7}{|c|}{ COMPRIMENTO DE ONDA NA FAIXA DO VISÍVEL } & \multicolumn{4}{|c|}{$\begin{array}{l}\text { COMPRIMENTOS DE ONDA NA } \\
\text { FAIXA DO INFRAVERMELHO }\end{array}$} \\
\hline & Blue & Cyan & Green & Yellow & Orange & Red & DeepRed & IR1 & IR2 & IR3 & IR4 \\
\hline$\lambda(\mathrm{nm})$ & 470 & 525 & 560 & 585 & 600 & 645 & 700 & 735 & 810 & 880 & 940 \\
\hline$\rho \operatorname{ref}(\%)$ & 87,8 & 84,2 & 80,7 & 79,8 & 79,7 & 87,7 & 95,1 & 96,6 & 96,8 & 97,3 & 95,8 \\
\hline
\end{tabular}

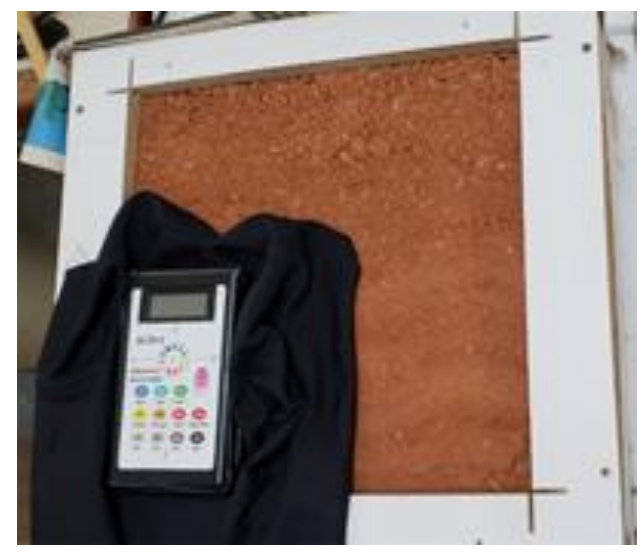

Figura 5: Posicionamento do equipamento ALTA II no corpo de prova.

b) Na sequência, as refletâncias espectrais da amostra em porcentagem (\%) foram derivadas para cada comprimento de onda por meio da Equação 1, onde $\rho_{\lambda \text {,amostra }}$ é a refletância da amostra para um determinado comprimento de onda (\%); $\mathrm{V}_{\lambda \text {,amostra }}$ a voltagem da amostra medida no comprimento de onda $(\mathrm{mV}) ; \mathrm{V}_{\mathrm{f} \text {,amostra }}$

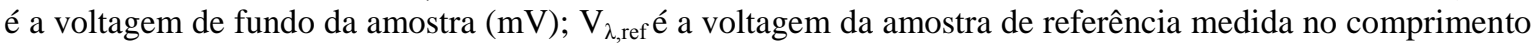


de onda $(\mathrm{mV}) ; \mathrm{V}_{\mathrm{f}, \text { ref }}$ é a voltagem de fundo da amostra de referência $(\mathrm{mV})$; e, $\rho_{\text {ref }}$ é a refletância da amostra de referência (já conhecida), no comprimento (\%).

$$
\rho_{\lambda, \text { amostra }}=\left(\frac{V_{\lambda, a m o s t r a}-V_{f, a m o s t r a}}{V_{\lambda, \text { ref }}-V_{f, r e f}}\right) \times \rho_{\text {ref }}
$$

O equipamento Alta II emite energia padronizada ao longo de todo comprimento de onda disponível no equipamento, devendo, portanto, os valores de refletância espectral obtidos serem convertidos para as intensidades verificadas no espectro da radiação solar, procedimento este feito por meio da utilização da norma técnica ASTM G173 [22]. Este procedimento é descrito na sequência.

A conversão consistiu em, primeiramente, transformar a refletância espectral (\%) em um valor adimensional, dividindo-a por 100. Após, a refletância espectral foi multiplicada pela irradiação solar global espectral em cada comprimento de onda (obtida na norma técnica ASTM G173 [22]), obtendo-se assim intensidade de irradiação do espectro solar padrão que seria refletida pela amostra, caso esta tivesse sido incidida pelo sol, no comprimento de onda analisado por meio da Equação 2, em que $\mathrm{G}_{(\lambda) \text { refletida }}$ é a Irradiação solar global espectral refletida pela amostra $\left(\mathrm{Wm}^{-2} \mathrm{~nm}^{-1}\right) ; \rho_{(\lambda)}$ é a Refletância espectral da amostra (adimensional); $\mathrm{G}_{(\lambda)}$ é a Irradiação solar global espectral $\left(\mathrm{Wm}^{-2} \mathrm{~nm}^{-1}\right)$.

$$
G_{(\lambda) \text { refletida }=\rho_{(\lambda)} \times G_{(\lambda)}}
$$

A intensidade de irradiação refletida pelo corpo de prova foi então integrada em cada um dos intervalos de comprimento de onda do equipamento (470nm a 940nm) por meio da Equação 3, onde $\mathrm{I}_{(\lambda \mathrm{x}-\mathrm{y}) \mathrm{refletida}}$ é a intensidade de radiação solar global refletida pela amostra no intervalo $\left(\mathrm{Wm}^{-2}\right), \mathrm{G}_{(\lambda \mathrm{x}) \text { refletida }}$ a irradiação solar global refletida pela amostra no comprimento de onda $\mathrm{x}\left(\mathrm{Wm}^{-2} \mathrm{~nm}^{-1}\right), \mathrm{G}(\lambda \mathrm{y})$ é a irradiação solar global refletida pela amostra no comprimento de onda y $\left(\mathrm{Wm}^{-2} \mathrm{~nm}^{-1}\right), \lambda \mathrm{x}$ é o comprimento de onda $\mathrm{x}(\mathrm{nm})$ e $\lambda \mathrm{y}$ é o comprimento de onda $\mathrm{y}$, sendo $\mathrm{y}>\mathrm{x}(\mathrm{nm})$.

$$
I_{\left(\lambda_{x-y}\right) \text { refletida }}=\left(\left(G_{\left(\lambda_{y}\right) \text { refletida }}+G_{\left(\lambda_{x}\right) \text { refletida }}\right) \div 2\right) \times\left(\lambda_{y}-\lambda_{x}\right)
$$

Posteriormente, a irradiação solar global foi integrada em todos os intervalos de comprimentos de onda do equipamento (470nm a 940nm) por meio da Equação 4, onde $\mathrm{I}_{(\lambda \mathrm{x} \text {-y) }}$ é a intensidade de irradiação solar global no intervalo $\left(\mathrm{Wm}^{2}{ }^{2}\right), \mathrm{G}_{(\lambda \mathrm{x})}$ é a irradiação solar global no comprimento de onda $\mathrm{x}\left(\mathrm{Wm}-{ }^{2} \mathrm{~nm}-1\right), \mathrm{G}_{(\lambda \mathrm{y})}$ é a irradiação solar global no comprimento de onda y (Wm- $\left.{ }^{2} \mathrm{~nm}-1\right)$, $\lambda \mathrm{x}$ é o comprimento de onda $\mathrm{x}$ (nm) e $\lambda \mathrm{y}$ é o comprimento de onda $\mathrm{y}$, sendo $\mathrm{y}>\mathrm{x}(\mathrm{nm})$.

$$
I_{\left(\lambda_{x-y}\right)}=\left(\left(G_{\left(\lambda_{y}\right)}+G_{\left(\lambda_{x}\right)}\right) \div 2\right) \times\left(\lambda_{y}-\lambda_{x}\right)
$$

A refletância solar ajustada ao espectro solar padrão foi então calculada por meio do quociente da soma das intensidades de irradiação refletida pela soma das intensidades de irradiação solar global (Equação 5), com $\rho_{\text {solar }}$ é a refletância solar ajustada $(\%), \mathrm{I}_{(\lambda x \text {-y)refletida }}$ é a intensidade de radiação solar global refletida pela amostra no intervalo ( $\left.\mathrm{Wm}^{2}\right)$ e $\mathrm{I}_{(\lambda x-y)}$ é a intensidade de irradiação solar global no intervalo (Wm-2 $)$.

$$
\rho_{\text {solar }}=\left(\frac{\sum_{\lambda=300(\lambda=2500) \text { refletida } I}^{\lambda=02500}}{\sum_{\lambda=300(\lambda x-y)}^{\lambda=1}}\right) \times 100
$$

c) Sendo a soma das parcelas de radiação refletida e absorvida igual ao total da radiação incidente, a absortância solar foi calculada a partir da refletância solar por meio da Equação 6, onde $\alpha$ é a absortância solar (adimensional); $\rho$ é a refletância solar (adimensional).

$$
\alpha=1-\rho
$$

\subsubsection{Câmara térmica}

O ensaio de transmitância térmica do corpo de prova foi realizado simulando uma medição in situ, conforme técnica de medição de fluxo de calor de acordo com a ISO 9869 [22], a partir da adaptação do método da caixa quente protegida da NBR 6488. A câmara térmica projetada possui dois compartimentos, um denominado como câmara quente (2) e outro denominado câmara ambiente (1), conforme representado no corte esquemático indicado na Figura 6com seus respectivos componentes. 


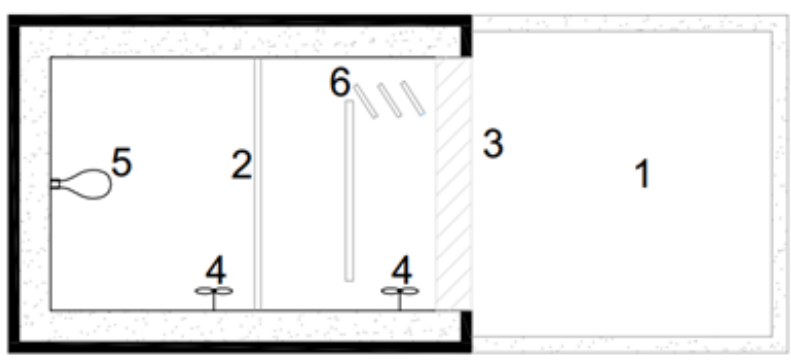

Figura 6: Representação esquemática em corte da câmara térmica. Legenda: 1- Câmara ambiente; 2- Câmara quente; 3Amostra; 4- Ventilador; 5- Lâmpada de infravermelho; e, 6- Chicanas para a circulação do ar no interior da câmara [23].

A parte denominada como câmara quente possui dimensões internas de $0,65 \mathrm{~m}$ x 0,50 m x 0,50 m, confeccionada com placas de madeira MDF (16 mm de espessura), placas de poliestireno expandido (25 e 50 $\mathrm{mm}$ de espessura), folhas de alumínio para revestimento do poliestireno, uma lâmpada de infravermelho (250 W) para produção de fonte de calor no interior da câmara, um dispositivo Dimmer para ajustar a intensidade da luz de infravermelho e chicanas para circulação do ar internamente. A parte denominada como câmara ambiental foi confeccionada em MDF $(16 \mathrm{~mm})$ e placas de poliestireno expandido $(25 \mathrm{~mm})$ com dimensões internas de $0,50 \mathrm{~m} \times 0,50 \mathrm{~m}$ x $0,35 \mathrm{~m}$, com o intuito de isolar o lado de fora do corpo de prova da exposição direta às condições climáticas externas (Figura 7).

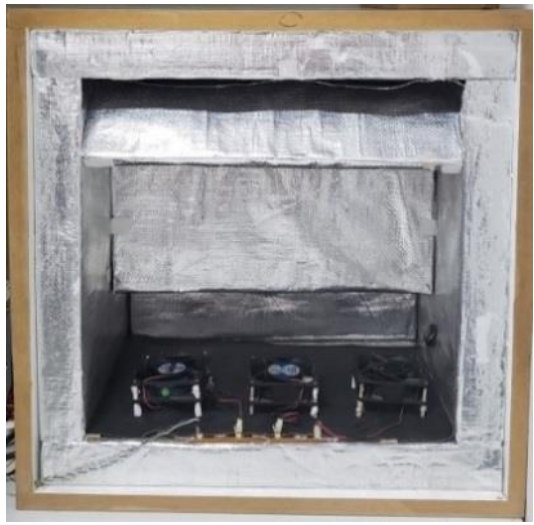

a)

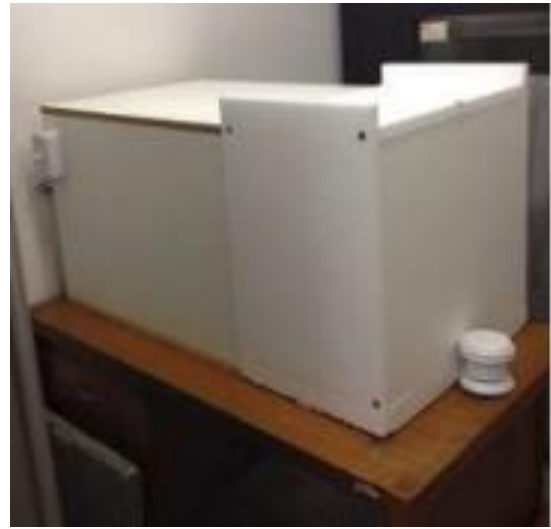

b)

Figura 7: a) Interior da câmara quente de ensaio, com placas de poliestireno expandido, revestidas por folhas de alumínio e lâmpada infravermelha) e b) câmara quente, câmara ambiental e Dimmer para ajuste de intensidade da luz de infravermelho [23].

\subsubsection{Ensaio de determinação da transmitância térmica (U) e análises de erro}

A transmitância térmica à radiação solar é uma propriedade que pode ser definida como o quociente da taxa de radiação solar que atravessa um elemento pela taxa de radiação solar incidente sobre este mesmo elemento[8]. É a variável mais importante para avaliar o comportamento térmico frente à transmissão de calor em elementos opacos [24]. Para a sua determinação, dispôs-se o corpo de prova entre a câmara quente e câmara ambiental, submetendo-o a uma diferença de temperatura $(\Delta T)$ entre suas faces, visando gerar um fluxo de calor (q) que pudesse ser medido por meio da técnica fluxométrica.

As faces do corpo de prova foram instrumentadas por sensores de temperatura do tipo NTC 10k para a medição da temperatura superficial interna $\left(\mathrm{T}_{\mathrm{si}}\right)$ e externa $\left(\mathrm{T}_{\mathrm{se}}\right)$. Dois sensores TMC20HD da marca OnsetComp foram instalados em cada face do corpo de prova, voltados para o interior e exterior da câmara quente e ambiental, respectivamente. Os sensores foram instalados na posição central (centrados com a fonte de calor), em posição vertical, numa área representativa do corpo de prova. Os dois sensores externos de temperatura foram posicionados entre o sensor de fluxo de calor (fluxímetro), modelo HFP01, fabricado por Hukseflux, instalado na posição vertical, visando medir o fluxo de calor que atravessa o corpo de prova.

A Figura 8-a ilustra o posicionamento para fixação do sensor de fluxo de calor no corpo de prova e a Figura 8-b e 6-c, os sensores de temperatura e de fluxo após fixação. 


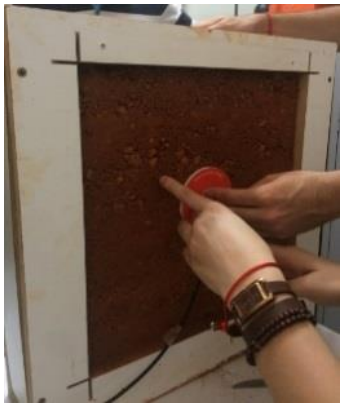

a)

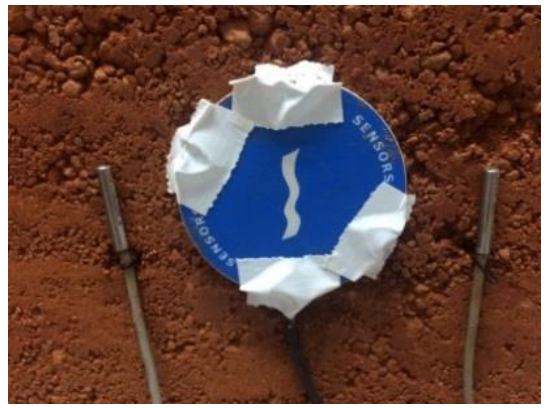

b)

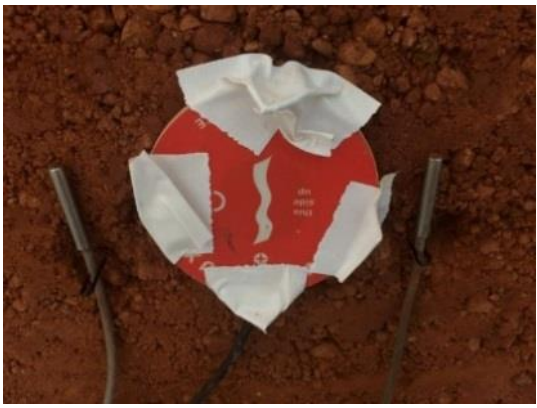

c)

Figura 8: Sensores de temperatura e fluxo de calor: a) Posicionamento do fluxímetro no eixo do corpo de prova; b) fixação dos sensores voltados para a parte externa; e, c) fixação dos sensores voltados para a parte interna

Foram utilizados grampos para fixação dos sensores na superfície do corpo de prova e, posteriormente, os mesmos foram cobertos por fita adesiva para evitar contato direto com o ar. Os sensores de temperatura foram conectados ao registrador de dados automático U12-13 da marca Onsetcomp e o sensor de fluxo de calor (fluxímetro), que avalia o fluxo de calor que passa pelo corpo de prova, foi acoplado a um amplificador de tensão e posteriormente a um registrador de dados automático U30 da marca Onsetcomp. A câmara ambiental foi inserida após a instalação de todos os sensores, com a finalidade de diminuir a influência das condições ambientais do espaço em que a mesma foi disposta.

Todos os sensores foram conectados a um registrador de dados para executar as leituras automáticas. Os dados foram coletados a cada 5 minutos durante 72 horas. Todos os equipamentos foram previamente calibrados.

Os registros foram transferidos para um computador por meio do software do fabricante dos equipamentos e, posteriormente, exportados para uma planilha eletrônica, para determinação dos parâmetros térmicos, conforme explicado a seguir:

a) Cálculo da transmitância térmica do corpo de prova

A transmitância (U) do corpo de prova, em $\mathrm{Wm}^{-2} \mathrm{~K}^{-1}$, foi calculada utilizando a média das temperaturas e das taxas de fluxo de calor através da espessura do corpo de prova em um período superior a 72 horas de medição após a condição de fluxo de calor estacionário ter sido alcançada.

Para a análise da medição, utilizou-se o método de média progressiva, conforme ISO 9869 [25], calculando-se a transmitância por meio da Equação 7, em que $U_{n}$ é a transmitância térmica para cada intervalo de medição $\left(\mathrm{Wm}^{-2} \mathrm{~K}^{-1}\right)$; $\mathrm{T}_{\mathrm{si}}$ é a temperatura interna $(\mathrm{K})$; $\mathrm{T}_{\mathrm{se}}$ é temperatura externa $(\mathrm{K})$; q é o fluxo de calor que atravessa o corpo de prova $\left(\mathrm{Wm}^{-2}\right)$; e, $\mathrm{j}$ é o intervalo de tempo das medições durante o ensaio do corpo de prova (5min).

$$
U_{n}=\frac{\sum_{j=1}^{n} q j}{\sum_{j=1}^{n}\left(T_{s i j}-T_{s e j}\right)}
$$

O cálculo de $\mathrm{U}_{\mathrm{n}}$ para cada medição foi feito sucessivamente, com o valor calculado convergindo assintoticamente para o valor estimado, uma vez seguidas as condições prescritas pela norma técnica ISO 9869 [25].

b) Análises de erro

A metodologia aplicada para estimar as incertezas no valor da transmitância térmica é denominada incerteza combinada [26]. Ela pode ser derivada a partir das incertezas das medições individuais dos sensores e o desvio padrão (s.d) observado no ensaio. A incerteza da medição foi avaliada assumindo-se o erro de calibração dos instrumentos declarado pelos fabricantes. Dessa forma, calculou-se a incerteza geral sobre a estimativa do valor $U(\delta U n)$, conforme Equação 8, em que $U_{\text {err_Tsi, }} U_{\text {err_Tse }}$ U $U_{\text {err_Q }}$ são os valores de $U$ calculados pela aplicação dos erros durante a medição das variáveis de temperatura interna, temperatura externa e fluxo de calor, em $\mathrm{Wm}^{-2} \mathrm{~K}^{-1}$.

$$
\delta U_{n}=\sqrt{\left[\left(U_{n}-U_{e r r_{-} T s i}\right)^{2}+\left(U_{n}-U_{e r r_{-} T s e}\right)^{2}+\left(U_{n}-U_{e r r_{Q}}\right)^{2}+S . D .^{2}\right]}
$$

Nas aplicações engenharia é usual expressar os resultados de um ensaio por meio de intervalo de con- 
fiança a partir da incerteza da medição [27]. Nesta estimativa, adotou-se como fator de abrangência (k) o valor igual a 2, uma vez que este é valor típico usualmente utilizado neste tipo de ensaio. A consideração deste fator de abrangência leva a um nível de confiança de $95 \%$ aproximadamente para a medição realizada.

Definido o fator de abrangência $(\mathrm{k})$, calculou-se o Intervalo de Confiança - $\mathrm{IC}_{0,95}(\mathrm{U})$ da medição por meio da Equação 9, em que U representa o intervalo no qual se espera que o valor transmitância térmica esteja compreendido com um nível de confiança de $95 \%$, sendo os demais termos definidos anteriormente.

$$
U=U_{n} \pm k \cdot \delta U_{n}
$$

\subsubsection{Cálculo de resistência térmica $\left(R_{T}\right)$, capacidade térmica total $\left(C_{T}\right)$, condutividade térmica $(\lambda)$ e atraso térmico $(\varphi)$}

Para o cálculo do atraso térmico, torna-se necessário primeiramente determinar as seguintes propriedades do corpo de prova: resistência térmica $\left(\mathrm{R}_{\mathrm{T}}\right)$, em $\mathrm{m}^{2} \mathrm{KW}^{-1}$, o calor específico (c), em $\mathrm{Jkg}^{-1} \mathrm{~K}^{-1}$, e a capacidade térmica $\left(\mathrm{C}_{\mathrm{T}}\right)$, em Jm $\mathrm{Jm}^{-2}$.

A resistência térmica é definida como o quociente da diferença de temperatura verificada entre as superfícies de um elemento ou componente construtivo pela densidade de fluxo de calor, em regime estacionário [8]. Esta pode ser calculada invertendo-se a transmitância térmica conforme Equação 10. No caso da resistência térmica total, expressa em $\left(\mathrm{m}^{2} \mathrm{KW}^{-1}\right)$, torna-se necessário somar à transmitância térmica do elemento ou componente, os valores da resistência térmica superficial interna e externa do $\operatorname{ar}\left(\mathrm{Wm}^{-2} \mathrm{~K}^{-1}\right)$.

$$
R_{T}=1 / U_{T}
$$

O calor específico foi calculado por meio da Equação 11 [28], na qual $\rho$ é a massa específica do material $\left(\mathrm{kgm}^{-3}\right)$; e é a espessura do corpo de prova $(\mathrm{m})$; A é a área do corpo de prova $\left(\mathrm{m}^{2}\right)$; q1 e q2 são os fluxos de calor médio interno e externo, respectivamente $(\mathrm{W})$; i a representação de cada medição; $\Delta \mathrm{t}$ a variação do tempo entre cada medição, em segundos; T1 e T2 são as médias das temperaturas interna $\left(\mathrm{T}_{\mathrm{si}}\right)$ e externa $\left(\mathrm{T}_{\mathrm{se}}\right)$, respectivamente $\left({ }^{\circ} \mathrm{C}\right)$; e, Ti é a temperatura inicial, associada a temperatura do ambiente no início das medições $\left({ }^{\circ} \mathrm{C}\right)$.

$$
c=\frac{1}{\rho e A}\left(\sum_{i=1}^{n} q 1-\sum_{i=1}^{n} q 2\right) \cdot \Delta t / \frac{(T 1+T 2)}{2}-T_{i}
$$

A condutividade térmica $(\lambda)$ [28], propriedade física de um material homogêneo e isótropo, onde se verifica um fluxo de calor constante, foi calculado por intermédio da Equação 12, em que $\lambda$ é a condutividade térmica do material, em $\mathrm{W}(\mathrm{m} . \mathrm{K})^{-1}$; q1 e q2 são os fluxos de calor médio interno e externo, respectivamente, em W; e é espessura do corpo de prova, em m; A é a área do corpo de prova, em m²; e, T1 e T2 são as temperaturas interna e externa, respectivamente, em ${ }^{\circ} \mathrm{C}$.

$$
\lambda=\frac{1}{2}(q 1+q 2) \frac{e}{A \cdot(T 1-T 2)}
$$

A capacidade térmica total $\left(\mathrm{C}_{\mathrm{T}}\right)$, definida como a quantidade de calor necessária para variar em uma unidade a temperatura de um sistema [8], foi determinada por meio da contribuição de cada elemento presente na estrutura do corpo de prova por meio da Equação 13, na qual $e$ é a espessura do corpo de prova (m); c é o calor específico médio obtido pela leitura dos fluxímetros $\left(\mathrm{Jkg}^{-1} \mathrm{~K}^{-1}\right)$ e $\rho$ é a massa específica $\left(\mathrm{kgm}^{-3}\right)$.

$$
C_{T}=\sum_{n=1}^{n} \lambda . R . c . \rho=\sum_{n=1}^{n} \text { e.c. } \rho
$$

Após a determinação dos parâmetros supracitados, obteve-se o atraso térmico $(\varphi)$, em horas, por meio da Equação 14, apresentada na norma técnica NBR 15220 [8], em que $\mathrm{R}_{\mathrm{T}}$ é a resistência térmica total $\left(\mathrm{m}^{2} \mathrm{KW}^{-1)}\right.$ e $\mathrm{C}_{\mathrm{T}}$ é a capacidade térmica do material $\left(\mathrm{Jm}^{-2} \mathrm{~K}^{-1}\right)$.

$$
\varphi=0,7284 \sqrt{R_{t} \cdot C_{t}}
$$

\subsubsection{Cálculo do fator solar (FSo)}

O fator solar representa o quociente da taxa de radiação solar transmitida através de um componente opaco pela taxa da radiação solar total incidente sobre a superfície externa do mesmo. Foi derivado por meio do uso de transmitância térmica e absortância para elementos opacos, o caso da taipa, por intermédio da Equação 15, em que $\mathrm{U}_{\mathrm{T}}$ é a transmitância térmica total do solo $\left(\mathrm{Wm}^{-2} \mathrm{~K}^{-1}\right)$ e $\alpha$ é a absortância do material (adimensional). 
$\mathrm{FS}=4 \cdot \mathrm{U} \cdot \alpha$

\subsubsection{Requisitos de norma para o desempenho térmico}

$\mathrm{Na}$ análise de desempenho térmico, estabeleceu-se que o corpo de prova deveria apresentar valores de absortância, transmitância térmica, atraso térmico, capacidade térmica e fator solar (obtidos por meio do ensaio e dos cálculos realizados) que proporcionem o atendimento aos parâmetros mínimos estabelecidos pelas normas técnicas NBR 15575-4 [9] e NBR 15220-3 [8] para Zona Bioclimática (Z) correspondente ao município de aplicação do solo (Cuiabá-Mato Grosso). No entanto, avaliou-se ainda a sua adequabilidade nas outras regiões brasileiras, conforme apresentado na Figura 9, tendo em vista a sua ocorrência em várias regiões do Brasil.

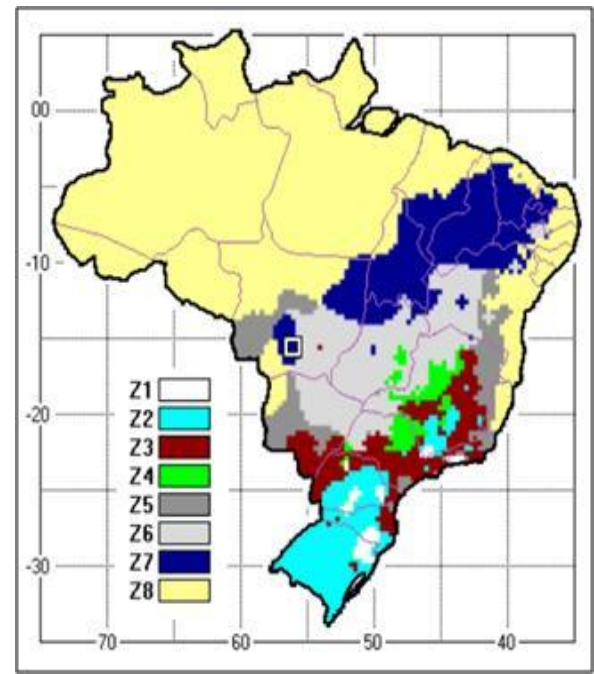

Município de Cuiabá

Figura 9: Zoneamento bioclimático brasileiro com demarcação do município de Cuiabá. Adaptado da norma técnica NBR 15220 [8].

A Tabela 2 apresenta as exigências da norma técnica NBR 15575-4 [9] relativas aos critérios para aceitação dos resultados de transmitância térmica e capacidade térmica.

Tabela 2: Requisitos para a transmitância térmica e capacidade térmica de paredes externas, estabelecidos pela norma técnica NBR 15575-4 [9].

\begin{tabular}{|c|c|c|c|c|}
\hline \multicolumn{3}{|c|}{ TRANSMITÂNCIA TÉRMICA (U) $\left(\mathrm{Wm}^{-2} \mathrm{~K}^{-1}\right)$} & \multicolumn{2}{|c|}{ CAPACIDADE TÉRMICA $\left(\mathrm{C}_{\mathrm{T}}\right)\left(\mathrm{KJ}\left(\mathrm{M}^{2} \cdot \mathrm{K}\right)^{-1}\right)$} \\
\hline Zona 1 e 2 & Zona 3, & 7 e 8 & Zona $1,2,3,4,5,6$ e 7 & Zona 8 \\
\hline \multirow{2}{*}{$\mathrm{U}_{\mathrm{T}} \leq 2,5$} & $\alpha^{*} \leq 0,6$ & $\alpha^{*}>0,6$ & \multirow{2}{*}{$\geq 130$} & \multirow{2}{*}{ Sem exigência } \\
\hline & $\mathrm{U}_{\mathrm{T}} \leq 3,7$ & $\mathrm{U}_{\mathrm{T}} \leq 2,5$ & & \\
\hline
\end{tabular}

*Sendo $\alpha$ a absortância à radiação solar da superfície externa da parede.

$\mathrm{O}$ atraso térmico e o fator de calor solar referentes às vedações verticais externas recomendados são apresentados na Tabela 3. Como é possível notar, a transmitância térmica definida na norma técnica NBR 15575-4 [9] é mais permissiva que na norma técnica NBR 15220 [8], enquanto que na segunda não há exigencia quanto a capacidade térmica, porem deve-se atenter as exigencias prescritas para o atraso térmico e fator solar. Nota-se, portanto, a presença de critérios dúbios entre a normativas, o que pode gerar dúvida a que critérios devem ser atendidos [28]. 
Tabela 3: Requisitos de transmitância térmica, atraso térmico e fator de calor solar, para vedação externa, recomendados pela norma técnica NBR 15220-3 [8].

\begin{tabular}{c|c|c|c}
\hline $\begin{array}{c}\text { VEDAÇÕES } \\
\text { EXTERNAS }\end{array}$ & $\begin{array}{c}\text { TRANSMITÂNCIA } \\
\text { TÉRMICA }(\mathbf{U})\left(\mathbf{W M}^{-2} \cdot \mathbf{K}^{-1}\right)\end{array}$ & $\begin{array}{c}\text { ATRASO TÉRMICO } \\
(\boldsymbol{\varphi}) \text { (HORAS) }\end{array}$ & $\begin{array}{c}\text { FATOR SOLAR } \\
\left(\mathbf{F S} \mathbf{S}_{\mathbf{0}}\right)(\%)\end{array}$ \\
\hline Parede leve & $\mathrm{U} \leq 3,00$ & $\varphi \leq 4,3$ & $\mathrm{Fs}_{\mathrm{o}} \leq 5,0$ \\
\hline Parede leve refletora & $\mathrm{U} \leq 3,60$ & $\varphi \leq 4,3$ & $\mathrm{Fs}_{\mathrm{o}} \leq 4,0$ \\
\hline Parede pesada & $\mathrm{U} \leq 2,20$ & $\varphi \geq 6,5$ & $\mathrm{Fs}_{\mathrm{o}} \leq 3,5$ \\
\hline
\end{tabular}

\section{RESULTADOS E DISCUSSÃO}

\subsection{Caracterização Geotécnica e compactação do solo}

A Tabela 4 apresenta sinteticamente os resultados de caracterização obtidos, os quais serão discutidos em seguida.

Tabela 4: Caracterização geotécnica do solo estudado.

\begin{tabular}{|c|c|c|}
\hline PROPRIEDADES & RESULTADO & NORMA DE REFERÊNCIA \\
\hline Pedregulho (\%) $(2 \mathrm{~mm} \leq \mathrm{d} \leq 20 \mathrm{~mm})$ & 68,00 & \multirow{6}{*}{ NBR 6502 [29] } \\
\hline Areia grossa $(\%)(0,6 \mathrm{~mm} \leq \mathrm{d}<2,0 \mathrm{~mm})$ & 5,00 & \\
\hline Areia média $(\%)(0,2 \mathrm{~mm} \leq \mathrm{d}<0,6 \mathrm{~mm})$ & 4,00 & \\
\hline Areia fina $(\%)(0,06 \mathrm{~mm} \leq \mathrm{d}<0,2 \mathrm{~mm})$ & 14,00 & \\
\hline Silte $(\%)(0,002 \leq \mathrm{d}<0,06)$ & 1,00 & \\
\hline Argila $(\%)(\mathrm{d}<0,002)$ & 8,00 & \\
\hline Teor de umidade higroscópica (\%) & 0,99 & NBR 6457 [13] \\
\hline Massa específica dos grãos $\left(\mathrm{g} / \mathrm{cm}^{3}\right)$ & 2,76 & ME 093 [16] \\
\hline Limite de plasticidade $(\%)$ & 24 & NBR $7180[15]$ \\
\hline Limite de liquidez (\%) & 36 & NBR 6459 [14] \\
\hline
\end{tabular}

a) Análise Granulométrica

Os resultados, de acordo com os critérios de avaliação da norma técnica NBR 6502 [29] evidenciam presença predominante de pedregulho, em torno de $68 \%$, seguido de areia $23 \%$ e silte e argila, com $1 \%$ e $8 \%$, respectivamente.

b) Umidade higroscópica

O valor médio de umidade higroscópica obtido segundo ensaio realizado foi $0,99 \%$. O percentual obtido foi adotado nos próximos cálculos para determinação da massa específica dos grãos.

c) Massa específica seca dos grãos

O valor médio da massa específica seca dos grãos do solo que passam na peneira de 4,75 mm é de $\delta=$ $2,76 \mathrm{~g} / \mathrm{cm}^{3}$. O valor obtido é superior ao comum médio adotado de $\delta=2,65 \mathrm{~g} / \mathrm{cm}^{3}$, o qual é baseado na massa específica do mineral quartzo, presente em grande quantidade na maioria dos solos.

d) Limites de consistência

Determinados LP de $24 \%$ e LL de 36\%, calculou-se o Índice de Plasticidade equivalente a $12 \%$, determinando o solo como medianamente plástico (7 < IP < 15) [30].

e) Compactação Proctor Normal

A obtenção desses dados foi determinante para a confecção do corpo de prova analisado na câmara térmica, o qual foi moldado com o solo com $14 \%$ de umidade.

A curva de compactação Proctor Normal foi obtida a partir do ensaio de sete corpos de prova, fornecendo como resultado massa específica seca máxima $\left(\delta_{\mathrm{d}}\right)$ de $1,98 \mathrm{~g} / \mathrm{cm}^{3}$ e teor de umidade ótimo $\left(\mathrm{w}_{\mathrm{ot}}\right)$ de $14 \%$, adotado para a confecção do corpo de prova analisado na câmara térmica. Ramos et al. [31] conduziram ensaio de Proctor Normal em solo de Latossolo Vermelho-Amarelo em área de cerrado nativo em região de 
Mato Grosso. Encontraram valores variando de 1,66 a $1,72 \mathrm{~g} / \mathrm{cm}^{3}$ para massa específica seca máxima e teor de umidade ótimo entre 11 a 12\%, valores próximos ao identificados nesta pesquisa.

Conforme exposto na Tabela 5, visando a aplicação em técnicas construtivas, pode-se classificar o solo após ensaio de compactação, a partir da massa específica máxima, em intervalos que variam de medíocre a excepcional. Para um valor de massa específica máxima igual a 1,98 $\mathrm{gcm}^{-3}$, o solo é muito satisfatório.

Tabela 5: Classificação do solo segundo a massa específica máxima após compactação. Adaptado de Doat et al. [31].

\begin{tabular}{l|l}
\hline MASSA ESPECÍFICA $\left(\mathbf{g c m}^{-3}\right)$ & CLASSIFICAÇÃO \\
\hline $1,65-1,76$ & Medíocre \\
\hline $1,76-2,10$ & Muito satisfatório \\
\hline $2,10-2,20$ & Excelente \\
\hline $2,20-2,40$ & Excepcional \\
\hline
\end{tabular}

\subsection{Determinações dos parâmetros de desempenho térmico}

Os índices de refletância e de absortância foram determinados mediante os cálculos realizados a partir das leituras de irradiação refletida, obtidas por meio do equipamento ALTA II. O corpo de prova em estudo apresentou refletância igual a de 38,37\% e, consequentemente, absortância igual a de 61,63\%. O valor de absortância determinado está dentro do intervalor estabelecido por Dornelles [32] para amostras de cores entre marrom e vermelha (de telha a vermelho cardinal), que variam de 61,2 a 70,6\%.

Na câmara térmica, a medição de temperaturas e fluxos de calor internos e externos, a cada 5 minutos, durante o período de 72 horas, totalizou 865 medições. Notou-se que, nas primeiras 24 horas, houve um período de oscilação nas temperaturas, até que o período estacionário fosse alcançado, verificando-se a estabilização das temperaturas tanto interna quanto interna. Comportamento semelhante foi observado para a transmitância térmica (Figura 10)

Consideraram-se para os cálculos as médias referentes a 288 registros, equivalentes as últimas 24 horas de medição. Obteve-se a temperatura superficial média externa $\left(\mathrm{T}_{\mathrm{se}}\right)$ de $40,37^{\circ} \mathrm{C}$ e a temperatura superficial média interna $\left(\mathrm{T}_{\mathrm{si}}\right)$ de $60,02^{\circ} \mathrm{C}$. $\mathrm{O}$ valor médio entre as diferenças de temperatura entre as faces interna e externa foi de aproximadamente $19,65^{\circ} \mathrm{C}$, enquanto fluxo de calor médio que atravessou o corpo de prova foi de $90,57 \mathrm{Wm}^{-2}$. Por meio destes valores, calculou-se a transmitância térmica para cada intervalo de medição $\left(\mathrm{U}_{\mathrm{n}}\right)$, podendo-se observar que os mesmos convergiram assintoticamente para o valor próximo ao real após o período de 24 horas, conforme desejado (Figura 10).

Figura 10: Temperatura superficial interna, temperatura superficial externa e transmitância térmica do corpo de prova

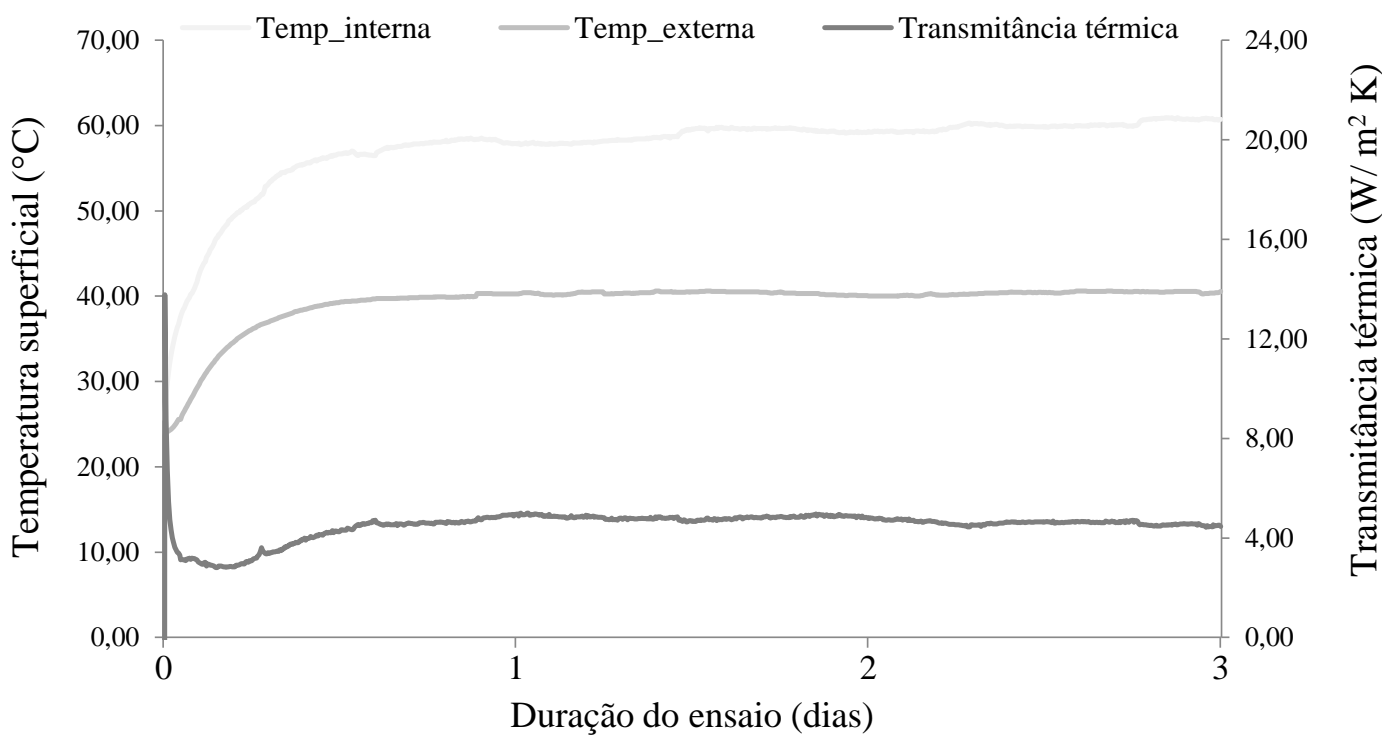


$\mathrm{O}$ valor médio de $\mathrm{U}_{\mathrm{n}}$ e a incerteza estatística da medição do ensaio foi de 4,61 $\pm 0,16 \mathrm{Wm}^{-2} \mathrm{~K}^{-1}$, que delimita o intervalo de confiança do ensaio $4,54 \leq \mathrm{U}_{\mathrm{n}} \leq 4,68 \mathrm{Wm}^{-2} \mathrm{~K}^{-1}$, enquanto que a resistência térmica foi de $0,217 \mathrm{~m}^{2} \mathrm{KW}^{-1}$ com intervalo de confiança entre $0,214 \leq \mathrm{R} \leq 0,220$.

A resistência térmica média total $\left(\mathrm{R}_{\mathrm{T}}\right)$ de $0,39 \mathrm{~m}^{2} \mathrm{KW}^{-1}$ foi calculada somando-se a média da resistência térmica com as resistências térmicas interna e externa do ar. Dessa forma, a transmitância média térmica total $\left(\mathrm{U}_{\mathrm{T}}\right)$ foi calculada pelo inverso da $\mathrm{R}_{\mathrm{T}}$, resultando em $2,58 \mathrm{Wm}^{-2} \mathrm{~K}^{-1}$. A Tabela 6 ilustra apresenta os valores determinados na estimativa do valor da transmitância $U_{n}$ e da incerteza da medição do corpo de prova e os resultados médios das propriedades térmicas do corpo de prova ensaiado.

Tabela 6: Estimativa do valor da transmitância Un e da incerteza na medição do corpo de prova.

\begin{tabular}{l|l|l}
\hline \multicolumn{2}{l}{ PARÂMETROS DE MEDIÇÃO } & VALORES MÉDIOS \\
\hline & Temperatura inicial ambiente & $26,87\left({ }^{\circ} \mathrm{C}\right)$ \\
\cline { 2 - 3 } & Diferença de temperatura & $19,65\left({ }^{\circ} \mathrm{C}\right)$ \\
\cline { 2 - 3 } Variáveis analisadas & Temperatura interna & $60,02\left({ }^{\circ} \mathrm{C}\right)$ \\
\cline { 2 - 3 } & Temperatura externa & $40,37\left({ }^{\circ} \mathrm{C}\right)$ \\
\cline { 2 - 3 } & Fluxo de calor & $90,57\left(\mathrm{Wm}^{2}\right)$ \\
\cline { 2 - 3 } & Valor de U médio & $4,61\left(\mathrm{Wm}^{2}\right)$ \\
\cline { 2 - 3 } & Incerteza $\delta U_{\mathrm{n}}$ & $0,25\left(\mathrm{Wm}^{2}\right)$ \\
\hline \multirow{4}{*}{ Análise de erro ${ }^{1}$} & Uerr_tsi & $4,67\left(\mathrm{Wm}^{2}\right)$ \\
\cline { 2 - 3 } & Uerr_Tse & $4,67\left(\mathrm{Wm}^{2}\right)$ \\
\cline { 2 - 3 } & Uerr_Q & $4,84\left(\mathrm{Wm}^{2}\right)$ \\
\cline { 2 - 3 } & Desvio-padrão & $0,07\left(\mathrm{Wm}^{2}\right)$ \\
\cline { 2 - 3 } & Percentagem de erro & $1,49 \%$ \\
\hline
\end{tabular}

${ }^{1}$ Uerr_Tsi, Uerr_Tse e Uerr_Q são os valores de transmitância térmica referentes as análises estatísticas de erros em relação as incertezas dos valores médios da temperatura superficial interna, temperatura superficial externa e fluxo, respectivamente.

A condutividade térmica do material foi equivalente a $0,56 \mathrm{~W}(\mathrm{~m} . \mathrm{K})^{-1}$, próxima ao valor indicado na norma técnica NBR 15220 [8] para solos $\left(0,52 \mathrm{~W}(\mathrm{~m} . \mathrm{K})^{-1}\right)$. A baixa condutividade térmica proporcionou um adequando isolamento térmico, uma vez que a diferença de temperatura entre a face interna e externa foi de aproximadamente $20^{\circ} \mathrm{C}$.

As propriedades definidas por intermédio da medição dos fluxos de calor no ensaio realizado no corpo de prova de terra compactada estão dispostas na Tabela 7.

Tabela 7: Propriedades térmicas do corpo de prova analisado.

\begin{tabular}{c|c|c|c|c}
\hline $\begin{array}{c}\text { Resistência Térmica } \\
\text { Total }\left(\mathbf{R}_{\mathbf{T}}\right) \\
\left(\mathbf{m}^{2} \mathbf{K W}^{-1}\right)\end{array}$ & $\begin{array}{c}\text { Transmitância Térmica } \\
\text { Total }\left(\mathbf{U}_{\mathbf{T}}\right) \\
\left(\mathbf{W m}^{-2} \mathbf{K}^{-1}\right)\end{array}$ & $\begin{array}{c}\text { Atraso Térmico }(\boldsymbol{\varphi}) \\
\mathbf{( h )}\end{array}$ & $\begin{array}{c}\text { Fator Solar }\left(\mathbf{F S}_{\mathrm{o}}\right) \\
(\%)\end{array}$ & $\begin{array}{c}\text { Capacidade Térmica }(\mathbf{C T}) \\
\left(\mathbf{k J m}^{-2} \mathbf{K}^{-1}\right)\end{array}$ \\
\hline 0,39 & 2,58 & 5,12 & 6,30 & 228,12 \\
\hline
\end{tabular}

Na Tabela 8 são apresentados os resultados da avaliação de conformidade das propriedades térmicas do corpo de prova em relação às exigências das normas NBR 15520 [8] e NBR 15575 [9], para as oito zonas bioclimáticas brasileiras.

Tabela 8: Atendimento dos requisitos normativos de propriedades térmicas, para as oito zonas bioclimáticas brasileiras.

\begin{tabular}{|c|c|c|c|c|c|c|c|c|c|}
\hline ZONAS BIOCLIMÁTICAS & Z1 & Z2 & Z3 & Z4 & Z5 & Z6 & $\mathbf{Z 7}$ & Z8 & REFERÊNCIA \\
\hline Transmitância Térmica (U) & $\mathrm{C}$ & $\mathrm{C}$ & $\mathrm{C}$ & $\mathrm{NC}$ & $\mathrm{C}$ & $\mathrm{NC}$ & $\mathrm{NC}$ & $\mathrm{C}$ & {$[8][9]$} \\
\hline Capacidade Térmica $\left(\mathrm{C}_{\mathrm{T}}\right)$ & $\mathrm{C}$ & $\mathrm{C}$ & $\mathrm{C}$ & $\mathrm{C}$ & $\mathrm{C}$ & $\mathrm{C}$ & $\mathrm{C}$ & $\mathrm{C}$ & [9] \\
\hline Atraso Térmico $(\varphi)$ & $\mathrm{NC}$ & $\mathrm{NC}$ & $\mathrm{NC}$ & $\mathrm{NC}$ & $\mathrm{NC}$ & $\mathrm{NC}$ & $\mathrm{NC}$ & $\mathrm{NC}$ & [8] \\
\hline Fator Solar $\left(\mathrm{FS}_{\mathrm{o}}\right)(\alpha=0,61)$ & $\mathrm{NC}$ & $\mathrm{NC}$ & $\mathrm{NC}$ & $\mathrm{NC}$ & $\mathrm{NC}$ & $\mathrm{NC}$ & $\mathrm{NC}$ & $\mathrm{NC}$ & [8] \\
\hline
\end{tabular}


C - Conforme; NC - Não conforme.

De acordo com a Tabela 8, observa-se que o corpo de prova de taipa apresentou resultados satisfatórios de transmitância térmica para Z1, Z2, Z3, Z5 e Z8. A capacidade térmica foi atendida em todas as zonas, diferente do atraso térmico, devido a espessura fina do corpo de prova, e o fator solar que, em virtude da cor marrom avermelhada do solo, condicionando-o a um alto valor de absortância térmica, não foram atendidos em nenhuma zona. Por outro lado, o simples fato de pintar o corpo de prova de uma cor mais clara, com absortância inferior a 0,4 , o FS o passa a ser atendido em todas as zonas.

Tendo em vista que na prática as paredes de taipa apresentam espessura em torno de $0,30 \mathrm{~m}$, projetaram-se os parâmetros térmicos a partir da condutividade térmica para essa espessura de parede $(\lambda=\mathrm{e} / \mathrm{R})$, conforme indicado na Tabela 9. É possível notar que com essa espessura, a parede atende a todos os requisitos das zonas 4, 6 e 7, sem a necessidade, inclusive, de pintura da parede.

Tabela 9: Propriedades térmicas do corpo de prova analisado.

\begin{tabular}{|c|c|c|c|c|}
\hline $\begin{array}{c}\text { Resistência Tér- } \\
\text { mica Total }\left(R_{T}\right) \\
\left(\mathbf{m}^{2} \mathrm{KW}^{-1}\right)\end{array}$ & $\begin{array}{c}\text { Transmitância Tér- } \\
\text { mica Total }\left(\mathrm{U}_{\mathrm{T}}\right) \\
\left(\mathrm{Wm}^{-2} \mathrm{~K}^{-1}\right)\end{array}$ & $\begin{array}{c}\text { Atraso Térmico } \\
(\varphi) \\
(\mathrm{h})\end{array}$ & $\begin{array}{c}\text { Fator Solar } \\
\left(\mathrm{FS}_{\mathrm{o}}\right) \\
(\%)\end{array}$ & $\begin{array}{c}\text { Capacidade Térmica } \\
(\mathrm{CT}) \\
\left(\mathrm{kJm}^{-2} \mathrm{~K}^{-1}\right)\end{array}$ \\
\hline 0,70 & 1,43 & 15,51 & 3,49 & 855,46 \\
\hline
\end{tabular}

Nota-se que o valor de $\mathrm{R}_{\mathrm{T}}$ está compreendido entre $0,35-0,70 \mathrm{~m}^{2} \mathrm{KW}^{-1}$ para uma mesma espessura de parede, conforme indicação da norma técnica australiana [33]. No entanto, em relação a $U_{T}$, o valor encontrado ficou ligeiramente inferior ao recomendado por Minke [4], compreendido entre $1,9-2,0 \mathrm{Wm}^{-2} \mathrm{~K}^{-1}$.

\section{CONCLUSÃO}

A terra é um material construtivo que pode ser utilizado na atualidade, atendendo os critérios de habitabilidade da sociedade contemporânea, desde que sejam empregadas em projetos modernos, com inovação tecnológica e que atendam a requisitos mínimos de conforto, resistência e durabilidade.

A taipa, técnica utilizada no Brasil e no mundo, tem mostrado inúmeras vantagens em termos sustentáveis, com baixas emissões de poluentes e demandando pouca água e energia no seu processo construtivo. Por outro lado, ainda existe uma carência de pesquisas atuais que possibilitem a validação do sistema construtivo com as normativas existentes. Em vista disso, esse trabalho fundamentou-se em realizar ensaios laboratoriais de caraterização do solo e de desempenho térmico de um corpo de prova compactado com características de umidade e densidade obtidas por meio do ensaio de Proctor normal.

Em relação ao ensaio térmico, o corpo de prova apresentou valores parcialmente consoantes aos parâmetros estabelecidos pela norma de desempenho térmico brasileira. Esse fato ocorreu em virtude do ensaio térmico conduzido ter sido realizado em um corpo de prova de espessura reduzida, o que não corresponde a prática observada em construções de taipa. No entanto, ao projetar a parede para as condições usuais (e = $0,30 \mathrm{~m})$, constatou-se que a mesma atende a todos os requisitos das zonas 4,6 e 7 . Confirmou-se que paredes de taipa sem estabilização, usualmente, não atendem aos níveis de isolamento térmico requeridos em climas frios, como verificado nas zonas 1, 2 e 3 .

Conclui-se, portanto, que o solo em estudo, se validado quanto a funções estruturais, pode ser utilizado em edificações nas zonas elencadas no Brasil, atendendo a normalização vigente quanto a desempenho térmico nas zonas indicadas.

\section{AGRADECIMENTOS}

Os autores agradecem aos órgãos financiadores e a todos os outros que apoiaram esta pesquisa: CAPES, FAPEMAT, Programa de Pós-graduação em Engenharia de Edificações e Ambiental (PPGEEA) da Universidade Federal de Mato Grosso (UFMT) e Laboratório de Tecnologia e Conforto Ambiental (LATECA).

\section{BIBLIOGRAFIA}

[1] FALCÃO, J., “Arquitectura Contemporânea em Terra”, Dissertação de M.Sc., Curso de Construção e Reabilitação, Instituto Superior Técnico, Lisboa, Portugal, 2014.

[2] TORGAL, F. P., JALALI, S., A sustentabilidade dos materiais de construção, 2 ed., Vila Verde, TecMi- 
nho, 2010.

[3] CASARES, R. G., "Arquitectura de tierra en el s.XXI", Trabalho de Conclusão de Curso, Escola Técnica Superior de Arquitetura de Madrid, Madrid, Espanha, 2017.

[4] MINKE, G., Building with earth. Design and technology of a sustainable architecture, 1 ed., BaselBerlin-Boston, Birkhäuser, 2006.

[5] HOFFMAN, M. V., MINTO, F. C. N., HEISE, A. F., "Taipa de Pilão", In: Técnicas de Construção em Terra, NESVES, C., FARIAS, O. B., v. 1, FEB/UNESP-PROTERRA, Bauru, pp. 46 - 61, 2011.

[6] HOUBEN, H. e GUILLAUD, H., Traité de construction en Terre, 1 ed., Marselha, Editions Parenthèses, 2006.

[7] GIORGI, P., "Avaliação de Desempenho de Sistema de Vedação Vertical de Bloco de Solo-Cimento Conforme NBR 15575 Referente à Habitabilidade e Sustentabilidade", Dissertação de M.Sc., UFSM, Santa Maria, RS, Brasil, 2016.

[8] ABNT - Associação Brasileira de Normas Técnicas. NBR 15520: Desempenho Térmico de Edificações, Rio de Janeiro, 2005.

[9] ABNT - Associação Brasileira de Normas Técnicas. NBR 15575-4: Edificações Habitacionais - Desempenho Parte 4: Sistemas de vedações verticais internas e externas - SVVI, Rio de Janeiro, 2012.

[10] SIG CUIABÁ - Sistema de Informação Geoambiental de Cuiabá, Várzea Grande e Entorno, Goiânia, CPRM, 2004.

[11] FOOKES, P. G., “Tropical Residual Soils”, In: Geological Society Professional Handbooks, pp. 09-40, 1997.

[12] ABNT - Associação Brasileira de Normas Técnicas. NBR 7181: Solo - Análise Granulométrica, Rio de Janeiro, 2016.

[13] ABNT - Associação Brasileira de Normas Técnicas. NBR 6457: Amostras de solo - Preparação para ensaios de compactação e ensaios de caracterização, Rio de Janeiro, 2016.

[14] ABNT - Associação Brasileira de Normas Técnicas. NBR 6459: Solo - Determinação do limite de liquidez, Rio de Janeiro, 2016.

[15] ABNT - Associação Brasileira de Normas Técnicas. NBR 7180: Solo - Determinação do limite de plasticidade, Rio de Janeiro, 2016.

[16] DNER - Departamento Nacional de Estradas de Rodagem. ME 093: Determinação da Densidade Real, Rio de Janeiro, 1994.

[17] ABNT - Associação Brasileira de Normas Técnicas. NBR 7182: Solo - Ensaio de Compactação, Rio de Janeiro, 2016.

[18] MANIATIDIS, V., WALKER, P., A Review of Rammed Earth Construction, Bath, Natural Building Technology Group Department of Architecture \& Civil Engineering University of Bath, UK, 2003.

[19] CB3E - Centro Brasileiro de Eficiência Energética em Edificações, Florianópolis: UFSC, Guia de medição e cálculo para refletância e absortância solar em superfícies opacas (v.1), 2015.

[20] DORNELLES, K. A. e RORIZ, M., "Identificação da absortância solar de superfícies opacas por meio de espectrômetro de baixo custo", In: $9^{\circ}$ Encontro Nacional de Tecnologia no Ambiente Construído, pp.314323, Florianópolis, 2006.

[21] CARDOSO, A. A., "Desempenho termo fisico e mecânico de argamassas de revestimento produzidas com resíduos sólidos poliméricos, minerais e vegetai", Dissertação de M.Sc., FAET - UFMT, Cuiabá, MT, Brasil, 2017.

[22] ASTM - American Society for Testing and Materials. G173 - 03 (Reapproved 2012): Standard Tables for Reference Solar Spectral Irradiances: Direct Normal and Hemispherical on $37^{\circ}$ Tilted Surface, West Conshohocken, 2012.

[23] NOGUEIRA, J. R. S., "Desempenho de painel de vedação vertical externa em steel framing composto por placas de madeira mineralizada", Dissertação de M.Sc. FAET - UFMT, Cuiabá, MT, Brasil, 2016.

[24] LAMBERTS, R., DUTRAL, L., PEREIRA, F. O. R., Eficiência energética na arquitetura, 3 ed, Rio de Janeiro, Eletrobras Procel, 2014.

[25] ISO - International Orhanization for Standardization. ISO 9869: Thermal insulation - Building elements - In - situ meansurement of thermal resistance and thermal transmitance, Pensilvânia, 2014. 
[26] BAKER, P., U values and traditional buildings. In situ measurements and their comparisons to calculated values, Glasgow Caledonian University, Historic Scotland Technical Paper 10, 2011.

[27] ABNT - Associação Brasileira de Normas Técnicas. NBR ISO 17025: Requisitos gerais para competência de laboratórios de ensaio e calibração. Rio de Janeiro, 2005.

[28] NICOLAU, V. P., GÜTHS, S., SILVA, M. G. "Thermal conductivity and specific heat measurement of low conductivity materials using heat flux meters", In: The Sixteenth European Conference on Thermophysical Properties, pp. 1 - 4, College, London, UK, 2002.

[29] CALLEJAS, I. J. A., DURANTE, L. C., SILVA. R. A. F., et al., "Verificação dos requisitos normativos de desempenho térmico em habitação de interesse social implantada em zona bioclimática 7”, In: $5^{\circ}$ Seminário Mato-grossense de Habitação de Interesse Social, Cuiabá, MT, Brasil, 2013.

[30] ABNT - Associação Brasileira de Normas Técnicas. NBR 6502: Rochas e Solos, Rio de Janeiro, 1995.

[31] CAPUTO, H. P., Mecânica dos solos e suas aplicações, 6 ed. Rio de Janeiro, Livros Técnicos e Científicos, 1987.

[32] RAMOS, F. T., RAMOS, D. T., MAIA, J. C. S., et al., "Curvas de compactação de um Latossolo Vermelho-Amarelo: Com e sem reuso de amostras”, R. Bras. Eng. Agríc. Ambiental, v. 17, n. 2, pp. 129-136, 2013.

[33] DORNELES, K. A. “Absortância solar de superfícies opacas: métodos de determinação e base de dados para tintas látex acrílica e PVA", Tese de D.Sc., Curso de Arquitetura e Urbanismo da USP, Campinas, SP, Brasil, 2008.

[34] SAI - Standards Australia International. HB 195: The Australian Earth Building Handbook, Sydney, Austrália, 2002.

[35] PEREIRA, J. P. B., SILVA, J. J. C. "Contributo para a melhoria do desempenho térmico das paredes de taipa”, In: Congresso Construção, vol. 4, pp. 1 - 12, Coimbra, 2012.

[36] FIORI, A. P. Fundamentos de mecânica dos solos e das rochas, 3 ed., São Paulo, Oficina de Textos, p. $576,2015$.

[37] DOAT, P., HAYAS, A., HOUBEN, H., et al., Construire en terre, Paris, CRATerre, 1979.

[38] VILLIBOR, D. F., NOGAMI, D. F. Pavimentos econômicos: tecnologia de uso dos solos finos lateríticos, São Paulo, Ed. Arte \& Ciência, p. 291, 2009.

\section{ORCID}

Carol Cardoso Moura Cordeiro

Douglas Queiroz Brandão

Luciane Cleonice Durante

Ivan Julio Apolônio Callejas

Caio Augusto Barbosa de Campos
https://orcid.org/0000-0003-3932-657X

https://orcid.org/0000-0001-8910-1163

https://orcid.org/0000-0002-4998-4587

https://orcid.org/0000-0001-7877-7029

https://orcid.org/0000-0003-3046-0211 